\title{
Striatal Dopamine D2/D3 Receptor Availability Varies Across Smoking Status
}

\author{
Corinde E Wiers", 1,3, Elizabeth A Cabrera',3, Dardo Tomasi', Christopher T Wong', Şükrü B Demiral', \\ Sung Won Kim', Gene-Jack Wang' and Nora D Volkow*, I,2 \\ 'National Institute on Alcohol Abuse and Alcoholism, National Institutes of Health, Bethesda, MD, USA; ${ }^{2}$ National Institute on Drug Abuse, \\ National Institutes of Health, Bethesda, MD, USA
}

\begin{abstract}
To assess how tobacco smoking status affects baseline dopamine D2/D3 (D2R) receptor availability and methylphenidate-induced dopamine (DA) release, we retrospectively analyzed D2R availability measures of 8 current smokers, 10 ex-smokers, and 18 nonsmokers who were scanned with positron emission tomography and [ $\left.{ }^{1} \mathrm{C}\right]$ raclopride, after administration of an injection of placebo or $0.5 \mathrm{mg} / \mathrm{kg}$ i.v. methylphenidate. There was a significant effect of smoking status on baseline striatal D2R availability; with current smokers showing lower striatal D2R availability compared with nonsmokers (caudate, putamen, and ventral striatum) and with ex-smokers (caudate and putamen). Baseline striatal D2R did not differ between nonsmokers and ex-smokers. The effect of smoking status on methylphenidate-induced DA release tended to be lower in smokers but the difference was not significant $(p=0.08)$. For behavioral measures, current smokers showed significantly higher aggression scores compared with both nonsmokers and ex-smokers. These results suggest that with abstinence exsmokers may recover from low striatal D2R availability and from increased behavioral aggression seen in active smokers. However, longitudinal studies are needed to assess this within abstaining smokers.

Neuropsychopharmacology (2017) 42, 2325-2332; doi: I 0.1038/npp.2017.131; published online 26 July 2017
\end{abstract}

\section{INTRODUCTION}

Cigarette smoking is one of the leading causes of preventable death and is often comorbid to psychiatric disorders including other substance use disorders (Albrecht et al, 2013; Busto et al, 2009). Although the prevalence of smoking has been steadily decreasing in the United States, it is still the number one cause of preventable death in the United States (Jamal et al, 2015). Moreover, treatment of nicotine addiction is challenging and only $15-25 \%$ of smokers who undergo a proven cessation program achieve abstinence at a 1 -year mark, even though the benefits of quitting smoking are well known (Fiore et al, 2008; Herman et al, 2014).

Nicotine, the main compound responsible for the addictiveness of cigarettes, binds to nicotinic acetylcholine receptors modulating the release of other neurotransmitters including acetylcholine, serotonin, glutamate, GABA, and dopamine (DA) (Herman et al, 2014). Particularly relevant to nicotine's rewarding effects is its ability to increase DA neuronal firing, thus increasing DA release into the nucleus

\footnotetext{
*Correspondence: Dr CE Wiers or Dr ND Volkow, National Institute on Alcohol Abuse and Alcoholism, Laboratory of Neuroimaging, National Institutes of Health, Room B2L I 24, I0 Center Drive, Bethesda, MD 20892, USA, Tel: +| 301 45। 3021 or Tel: +| 3014020868 , Fax: I 30 | 402 0868, E-mail: corinde.wiers@nih.gov or nvolkow@nida.nih.gov

${ }^{3}$ These two authors contributed equally to this work.

Received 8 March 2017; revised 7 June 2017; accepted II June 2017; accepted article preview online 23 June 2017
}

accumbens, a common mechanism underlying the rewarding effects of drugs of abuse (Brody et al, 2009). Neuroplastic changes in the brain dopamine reward pathway and associated circuits are believed to underlie the inability to refrain from smoking in nicotine addiction. (Dani, 2003).

DA neurotransmission can be measured in the human brain using positron emission tomography (PET) and radiotracers such as $\left[{ }^{11} \mathrm{C}\right]$ raclopride, a DA D2/D3 receptor (D2R) antagonist ligand that competes with endogenous dopamine for binding to D2R. Thus, comparison of $\left[{ }^{11} \mathrm{C}\right]$ raclopride's binding after placebo from that after a challenge with a stimulant drug such as methylphenidate (MP) serves as an estimate of DA release (Volkow et al, 1994). MP dosedependently blocks the DA transporters (Volkow et al, 1998) resulting in increased extracellular DA levels and a concomitant dose-related decrease in binding of $\left[{ }^{11} \mathrm{C}\right]$ raclopride in the striatum (Volkow et al, 1999, 20012b). Most studies have consistently shown lower striatal baseline D2R availability and MP-induced DA increases in participants with different substance use disorders including cocaine, methamphetamine, and alcohol as compared with healthy controls (Martinez et al, 2005; Volkow et al, 2014a; Wang et al, 2012). Similarly, studies using the stimulant drug amphetamine as challenge have also documented attenuated DA increases in alcoholics (Martinez et al, 2005) and cocaine abusers (Martinez et al, 2007), whereas in marijuana abusers some studies have reported decreased responses (van de Giessen et al, 2017; Volkow et al, 2014b) and in others no changes (Mizrahi et al, 2013; Urban et al, 2012). 
Studies in heavy cigarette smokers have also reported decreased striatal D2R availability compared with nonsmoking controls using PET and the D2R radiotracers $\left[{ }^{11} \mathrm{C}\right]$ raclopride (Albrecht et al, 2013) and $\left[{ }^{18} \mathrm{~F}\right]$ fallypride (Brown et al, 2012; Fehr et al, 2008). Moreover, smoking a cigarette in current smokers decreased D2R availability in ventral striatum (VS), suggesting occupancy of D2R by nicotineinduced DA increases (Brody et al, 2004). Studies on the effects of smoking on stimulant-induced DA release have, however, been limited. There is only one published study in depressed smokers that showed increased DA release (assessed with $\left[{ }^{11} \mathrm{C}\right]$ raclopride and an amphetamine challenge) compared with nonsmoking depressed subjects and with healthy controls (Busto et al, 2009). Surprisingly, no previous study has investigated differences in striatal D2R availability and/or DA release in current smokers versus former smokers.

The purpose of this retrospective study was to evaluate the effect of smoking status on baseline striatal D2R and MPinduced DA release. We therefore analyzed $\left[{ }^{11} \mathrm{C}\right]$ raclopride PET scans of a group of current smokers, ex-smokers, and nonsmokers. All participants underwent PET scanning after placebo and after MP administration. Current smokers and ex-smokers were matched for smoking characteristics and demographics. We hypothesized, first, that current smokers would show lower baseline striatal D2R availability compared with controls, as previously shown by Albrecht et al (2013). Second, we expected blunted MP-induced striatal DA release in current smokers versus nonsmokers, as seen in patients with substance use disorders other than smoking (Volkow et al, 2007, 2014a; Wang et al, 2012). Third, we hypothesized that ex-smokers would have baseline striatal D2R and MP-induced DA release similar to that of nonsmokers, as seen in other drug users after a period of abstinence (Rominger et al, 2012).

Previous studies have shown that behavioral aggression is higher in smokers compared with nonsmokers and exsmokers (Cui et al, 2016; Kahler et al, 2009), and DA signaling has been implicated in the regulation of aggressive behavior (Couppis et al, 2008; van Erp and Miczek, 2000; Yamaguchi et al, 2017). We therefore also tested the effect of smoking status on personality traits including aggression, and explored its associations with dopaminergic measures.

\section{MATERIALS AND METHODS}

\section{Participants}

PET data were selected from 8 current smokers (2 female), 10 ex-smokers ( 3 female), and 18 nonsmokers (6 female) who participated as healthy volunteers in previous studies at Brookhaven National Laboratory between May 2002 and December 2012 (see, eg, Shumay et al, 2017; Volkow et al, 2012b, 2014a, b). All participants participated once, and groups of smokers and ex-smokers consist of different individuals. Participants underwent screening that included a detailed medical history, physical, psychiatric, and neurological examinations, EKG, breath CO, routine blood tests and

Table I Demographics and Smoking Characteristics of Current Smokers, Ex-Smokers, and Nonsmokers

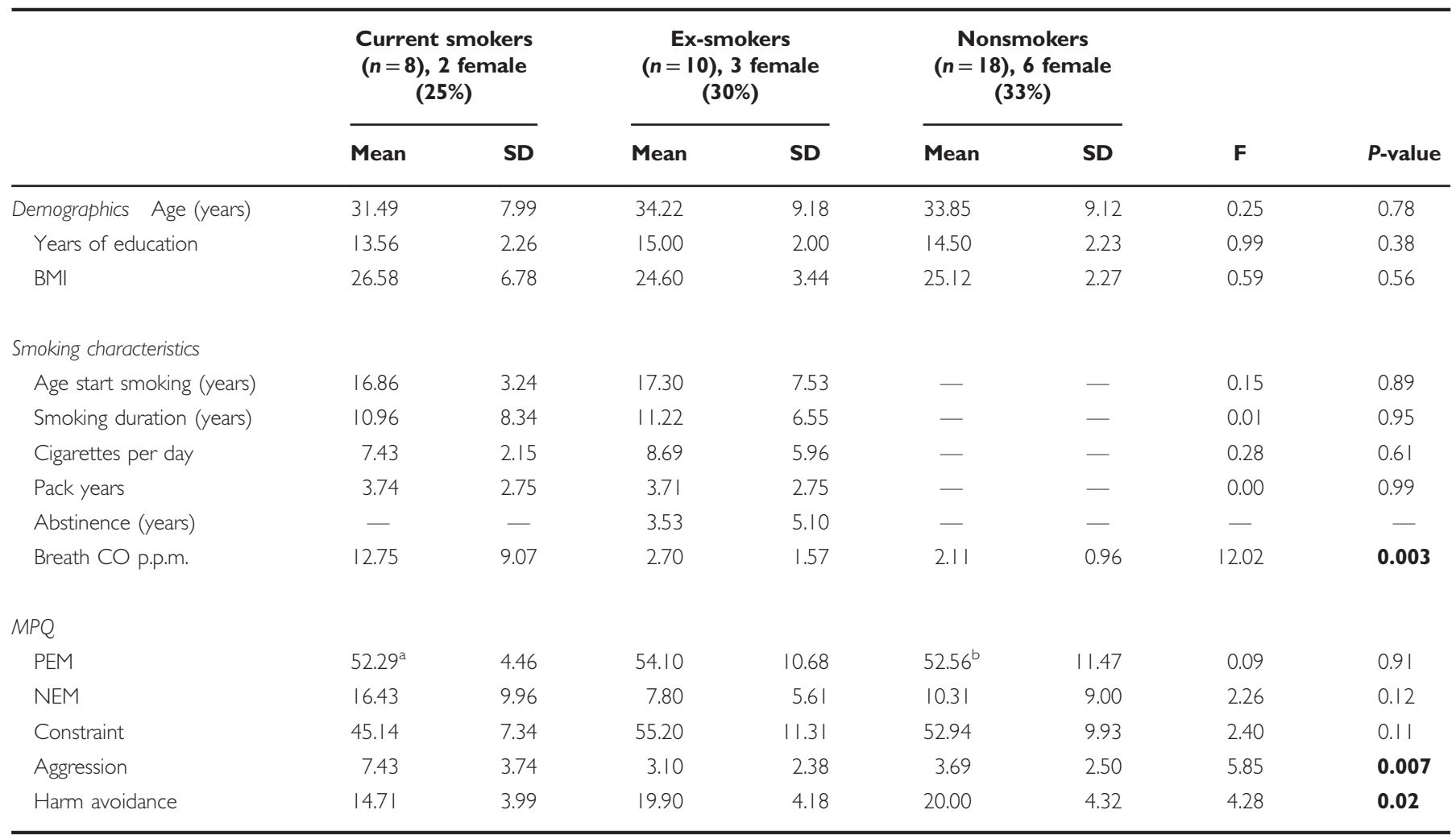

Abbreviations: BMI, body mass index; CO, carbon monoxide; MPQ, Multidimensional Personality Questionnaire; NEM, negative emotionality; PEM, positive emotionality; p.p.m., parts per million.

For personality scores, data were available for ${ }^{a} n=7$ smokers, $n=10$ ex-smokers, and ${ }^{b} n=16$ non-smokers. $P$-values in bold are significant $(P<0.05)$. 
urinalysis, and urine toxicology for psychotropic drugs. Exclusion criteria for all participants included current or past psychiatric disorder; past or present history of neurological, cardiovascular, or endocrinological disease; history of head trauma with loss of consciousness of $>30 \mathrm{~min}$; use of psychoactive medications in the past month; and current medical illness and drug abuse or dependence other than nicotine. Urine drug screens and breathalyzer were negative on the day of testing. Three participants (1 current smoker, 2 ex-smokers) reported past marijuana use ( $>6$ years before the study), but did not meet criteria for abuse. Studies were approved by the Committee on Research Involving Human Subjects at Stony Brook University and the Radioactive Drug Research Committee at Brookhaven National Laboratory. All participants granted written informed consent before beginning the PET study.

Groups of current smokers, ex-smokers, and nonsmokers were matched for age, gender, years of education, and BMI (see Table 1 for means and group statistics). The groups of current smokers and ex-smoker had matched smoking patterns, with similar smoking starting age, smoking duration, cigarettes per day, and pack years (packs smoked per day $\times$ years of smoking). However, breath CO levels were significantly higher in current smokers compared with ex-smokers and nonsmokers, indicating abstinence in the ex-smoking group. Ex-smokers were abstinent of cigarette smoking for an average of 3.5 years $\pm 5.1 \mathrm{SD}$, ranging from 6 months to 15 years. Nonsmokers reported not having smoked in the past, other than having experimented on a few occasions.

\section{Personality Questionnaire}

Participants completed the Multidimensional Personality Questionnaire (MPQ) (Patrick et al, 2002) that has three main factors: positive emotionality (PEM), negative emotionality (NEM), and constraint. Two of the second-order factors, aggression and harm avoidance, were also analyzed because of previous research suggesting differences in these factors between current smokers and nonsmokers (Cui et al, 2016).

\section{PET Imaging and Processing}

Imaging was done at the BNL Brain Imaging Center on a Siemens HR+ scanner (resolution $4.5 \times 4.5 \times 4.5 \mathrm{~mm}$ fullwidth half-maximum, 63 slices) using procedures previously described for subjects positioning and scanning protocol (Volkow et al, 1994). In summary, each subject underwent two $\left[{ }^{11} \mathrm{C}\right]$ raclopride scans on the same day. The first scan was done under the placebo condition ( $3 \mathrm{ml}$ i.v. saline) and the second was done after MP (0.5 mg/kg i.v.). Dynamic scans were started immediately after injection of $4-10 \mathrm{mCi}$ (specific activity $0.5-1.5 \mathrm{Ci} / \mu \mathrm{M}$ at time of injection) and were obtained for $60 \mathrm{~min}$. There were no between-group differences for injected $\left[{ }^{11} \mathrm{C}\right]$ raclopride dose per body weight (mean placebo: current smokers $=0.071 \mathrm{mCi} / \mathrm{kg} \pm 0.02 \mathrm{SD}$, ex-smokers $=0.088 \pm 0.03$, nonsmokers $=0.084 \pm 0.02, F_{2,34}$ $=1.3, p=0.3 ; \mathrm{MP}$ : current smokers $=0.086 \mathrm{mCi} / \mathrm{kg} \pm 0.02$ $\mathrm{SD}$, ex-smokers $=0.085 \pm 0.03$, nonsmokers $=0.080 \pm 0.02$, $\mathrm{F}_{2,34}=0.3, p=0.8$ ). The concentration of total carbon-11 and unchanged $\left[{ }^{11} \mathrm{C}\right]$ raclopride in plasma was calculated from blood drawn through arterial sampling. Participants in the smoking group were free from cigarette smoking for at least $2.5 \mathrm{~h}$ before scanning.

For the purpose of the study, regional nondisplaceable binding potential $\left(\mathrm{BP}_{\mathrm{ND}}\right)$ values were computed for handdrawn caudate, putamen, and VS using a procedure previously described (Wang et al, 1999). ROIs were obtained from three sequential axial planes where ROIs were most visible and had the same size and shape across subjects within neuroanatomically defined bilateral caudate, putamen, and VS: $2.2,2.2$, and $0.8 \mathrm{~cm}^{3}$, respectively. The ratio of the distribution volume in striatal regions was computed to that in the cerebellum to obtain $\mathrm{BP}_{\mathrm{ND}}$ that was used to quantify D2R availability (Logan et al, 1996). The difference in $\mathrm{BP}_{\mathrm{ND}}$ for caudate, putamen, and VS between the MP and the placebo conditions $\left(\mathrm{BP}_{\mathrm{ND}}\right.$ placebo- $\left.\mathrm{BP}_{\mathrm{ND}} \mathrm{MP}\right)$ was calculated to estimate MP-induced DA release (Volkow et al, 1997, 2012a, 2014a, b). Moreover, we report the percent signal change between placebo and $\mathrm{MP}$ : $\left(\mathrm{BP}_{\mathrm{ND}}\right.$ placebo$\mathrm{BP}_{\mathrm{ND}} \mathrm{MP}$ ) $/ \mathrm{BP}_{\mathrm{ND}}$ placebo $\times 100 \%$ (Innis et al, 2007; Martinez et al, 2005).

\section{Statistical Analyses}

All analyses were performed using SPSS 22 (IBM, Armonk, NY). Outliers that were $>3$ SDs were removed from analyses.

For striatal baseline D2R availability and MP-induced DA release, we performed two separate multivariate analyses of covariance (MANCOVA) with (1) baseline D2R or (2) MPinduced DA release in caudate, putamen, and VS as dependent variables, and smoking status as between-group variable, with univariate analyses for each region to test directions of effects. Significance levels were set at $\alpha=0.05$, and results at $p<0.1$ were reported as trends. The post hoc $t$-tests were performed for 9 between-group comparisons, with a Bonferroni-corrected $\alpha$ threshold of 0.006 (ie, 0.05/9). We covaried for age and BMI, as these have been negatively correlated with striatal D2R in previous studies (Dang et al, 2016; Ishibashi et al, 2009; Volkow et al, 2000). In the current sample, striatal D2R also showed significant negative correlation with age (caudate $r=-0.64, p<0.0001$; putamen $r=-0.67, p<0.0001$ and VS: $r=-0.41, p=0.01$ ), but not with BMI $(p>0.3)$. Scanning date (range: May 2002 to December 2012) did not correlate with either baseline D2R $(p>0.2)$ or DA release $(p>0.3)$ and we did not include it as a covariate to the PET analyses.

MPQ dimensions were analyzed using one-way ANOVAs with the three groups (smokers, ex-smokers, and nonsmokers) as between-group variable. Significance levels were corrected for multiple comparisons at $\alpha=0.017$ (ie, 0.05/3). We also explored the correlation of MPQ dimensions aggression and harm avoidance with D2R availability in each group (6 comparisons), and MP-induced DA release (6 comparisons) with a corrected $\alpha$ threshold of 0.008 (ie, $0.05 / 6)$. Significant levels of $p<0.1$ were reported as trends.

\section{RESULTS}

There were no outliers for baseline or MP-induced DA release that exceeded $3 \mathrm{SD}$ for any striatal region $(p>0.1)$. 


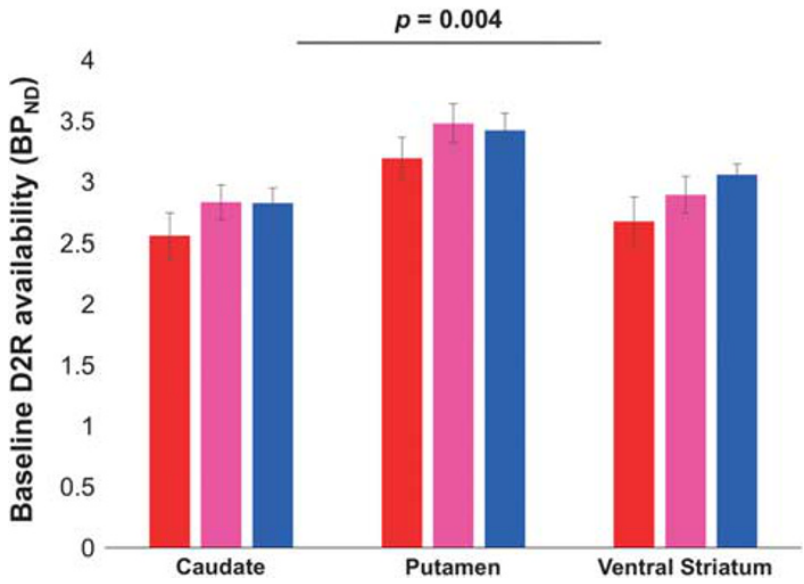

Figure I Smoking status had a significant effect on striatal D2R availability $(p=0.004)$, with post hoc tests showing reduced D2R availability in smokers versus nonsmokers (caudate $p=0.015$, putamen $p=0.035$, ventral striatum $p=0.012$ ) and ex-smokers (caudate $p=0.05$ and putamen $p=0.03$ ). The post hoc effects did not meet Bonferroni correction for multiple comparisons (all $p>0.006$ ). Error bars represent I SEM. Statistics were corrected for age and $\mathrm{BMI}$. BP $\mathrm{ND}_{\mathrm{ND}}$, nondisplaceable binding potential; $\mathrm{D} 2 \mathrm{R}$, dopamine D2/D3 receptor.

The MANCOVA showed a significant effect of smoking status on baseline striatal D2R availability $(\theta=0.55$, $\mathrm{F}_{3,30}=5.45, p=0.004, \eta^{2}=0.35$; Figure 1).

Separate ANCOVAs showed that effects were significant for caudate $\left(\mathrm{F}_{2,31}=3.5, p=0.043, \eta^{2}=0.18\right)$, VS $\left(\mathrm{F}_{2,31}=4.2\right.$, $\left.p=0.024, \quad \eta^{2}=0.21\right)$, and at trend level in putamen $\left(\mathrm{F}_{2,31}=3.1, p=0.059, \eta^{2}=0.17\right)$ (see Table 2). The post hoc $t$-tests showed that smokers had reduced D2R availability compared with nonsmokers in all striatal regions (caudate: $t=2.6, p=0.015$; VS: $t=2.7, p=0.012$; and putamen: $t=2.2$, $p=0.035)$, and compared with ex-smokers in caudate $(\mathrm{t}=2.2, p=0.05)$ and putamen $(\mathrm{t}=2.4, p=0.03)$, but not VS $(p>0.01)$. However, the post hoc effects did not meet Bonferroni correction for multiple comparisons (all $p>0.006)$. There were no group differences between exand nonsmokers.

There was a trend-wise effect of smoking status on DA release (MANCOVA: $\theta=0.19, \quad \mathrm{~F}_{3,30}=2.49, \quad p=0.08$, $\left.\eta^{2}=0.20\right)$ that was because of a significant univariate effect in the putamen $\left(\mathrm{F}_{2,31}=3.5, p=0.04, \eta^{2}=0.19\right)$, at trend level in caudate $\left(\mathrm{F}_{2,31}=3.2, p=0.057, \eta^{2}=0.17\right)$, but not in VS $(p=0.13)$ (see Table 2). Exploratory post hoc tests showed increased DA release in ex-smokers compared with current smokers for caudate $(t=1.9 p=0.08)$ and putamen $(t=2.0$ $p=0.06)$ at trend level (Figure 2), but not in VS $(p>0.1)$. Exsmokers also had stronger DA release than nonsmokers in caudate $(t=2.2, p=0.04)$, putamen $(t=2.4, p=0.03)$ and VS $(t=1.9, p=0.08)$. None of the post hoc effects met Bonferroni correction for multiple comparisons (all $p>0.006)$. There were no differences between current smokers and nonsmokers. Table 2 provides means of methylpenidate-induced $\mathrm{DA}$ release $\left(\mathrm{BP}_{\mathrm{ND}}\right.$ placebo- $\mathrm{BP} \mathrm{P}_{\mathrm{ND}}$ $\mathrm{MP})$ and percent signal change $\left(\mathrm{BP}_{\mathrm{ND}}\right.$ placebo- $\left.\mathrm{BP}_{\mathrm{ND}} \mathrm{MP}\right) /$ $\mathrm{BP}_{\mathrm{ND}}$ placebo $\times 100 \%$.
- Current Smokers $(n=8)$

= Ex-smokers $(n=10)$

- Non-smokers $(n=18)$

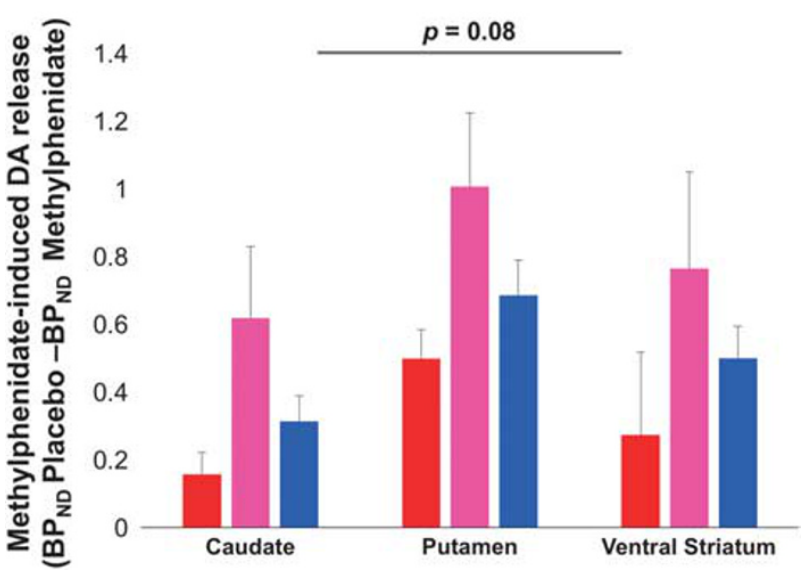

Figure 2 Methylphenidate-induced DA release varied over smoking status at trend level $(p=0.08)$. Exploratory post hoc tests showed increased DA release in ex-smokers compared with current smokers at trend level for caudate $(p=0.08)$ and putamen $(p=0.06)$, and compared with nonsmokers in caudate $(p=0.04)$, putamen $(p=0.03)$, and VS $(p=0.08)$. The post hoc effects did not meet Bonferroni correction for multiple comparisons (all $p>0.006$ ). Error bars represent I SEM. Statistics were corrected for age and $\mathrm{BMI}$. $\mathrm{BP}_{\mathrm{ND}}$, nondisplaceable binding potential; $\mathrm{DA}$, dopamine.

\section{Personality}

NEM, PEM, and Constraint were not significantly different between smoking groups $(p>0.1)$. However, there was a significant effect of smoking status on MPQ aggression $\left(\mathrm{F}_{2,30}=5.85, p=0.007 \eta^{2}=0.28\right.$; Bonferroni corrected $)$ and for harm avoidance $\left(\mathrm{F}_{2,30}=4.28, \quad p=0.023 ; \eta^{2}=0.22\right)$. Smokers had elevated aggression scores and lower harm avoidance scores compared with nonsmokers $(t=2.8$, $p=0.010 ; t=2.8, p=0.012)$ and compared with ex-smokers $(t=2.9, p=0.010$; trend level: $t=2.6, p=0.022)$. There were no differences between ex-smokers and nonsmokers $(p>0.1)$.

Exploratory analyses showed no associations between aggression or harm avoidance personality scores with baseline D2R or MP-induced DA release in participants pooled together $(p>0.1$, corrected for age and BMI). In nonsmokers only, aggression correlated with baseline D2R in putamen $(r=0.72, p=0.004$; Bonferroni corrected), VS $(r=0.56, p=0.04)$, and caudate $(r=0.47, p=0.09)$ at trend level (Figure 3). There were no significant correlations for MP-induced DA release (all $p>0.1$, corrected for age and $\mathrm{BMI})$.

\section{DISCUSSION}

Here we show lower baseline striatal D2R availability in current smokers compared with nonsmokers that were significant for caudate and VS and, at trend level, in putamen. Current smokers also exhibited lower D2R availability than ex-smokers in caudate and putamen. However, we did not find evidence for significant differences on striatal DA release after MP administration between current smokers and nonsmokers, although ex-smokers 
Table $2 \mathrm{BP}_{\mathrm{ND}}$ and Methylphenidate-Induced Dopamine Release $(\mathrm{PL}-\mathrm{MP})$ and Percent Signal Change $(\mathrm{PL}-\mathrm{MP}) / \mathrm{PL}$

\begin{tabular}{|c|c|c|c|c|c|c|c|c|}
\hline \multirow[b]{2}{*}{$\mathbf{B P}_{\mathbf{N D}}$} & \multicolumn{2}{|c|}{ Smokers $(n=8)$} & \multicolumn{2}{|c|}{ Ex-smokers $(n=10$} & \multicolumn{2}{|c|}{$\begin{array}{l}\text { Nonsmokers } \\
\quad(n=18)\end{array}$} & \multirow[b]{2}{*}{$\mathbf{F}$} & \multirow[b]{2}{*}{$P$-value } \\
\hline & Mean & SD & Mean & SD & Mean & SD & & \\
\hline Caudate placebo & 2.55 & 0.53 & 2.83 & 0.45 & 2.82 & 0.52 & 3.49 & 0.04 \\
\hline MP & 2.40 & 0.51 & 2.21 & 0.89 & 2.51 & 0.50 & 0.82 & 0.45 \\
\hline Putamen placebo & 3.19 & 0.49 & 3.48 & 0.51 & 3.42 & 0.59 & 3.11 & 0.06 \\
\hline MP & 2.69 & 0.51 & 2.47 & 0.92 & 2.74 & 0.41 & 0.57 & 0.57 \\
\hline$P L-M P$ & 0.50 & 0.24 & 1.01 & 0.69 & 0.68 & 0.44 & 3.53 & 0.04 \\
\hline \% Change & 15.70 & 7.21 & 29.98 & 25.69 & 18.93 & 10.90 & 2.58 & 0.09 \\
\hline$P L-M P$ & 0.27 & 0.69 & 0.76 & 0.90 & 0.50 & 0.40 & 2.24 & 0.12 \\
\hline \% Change & 6.17 & 29.25 & 24.03 & 31.54 & 16.05 & 12.11 & 2.23 & 0.13 \\
\hline
\end{tabular}

Abbreviations: $\mathrm{BP}_{\mathrm{ND}}$, nondisplaceable binding potential; $\mathrm{MP}$, methylphenidate; $\mathrm{PL}$, placebo; $\mathrm{VS}$, ventral striatum.

$P$-values in bold are significant $(P<0.05)$.
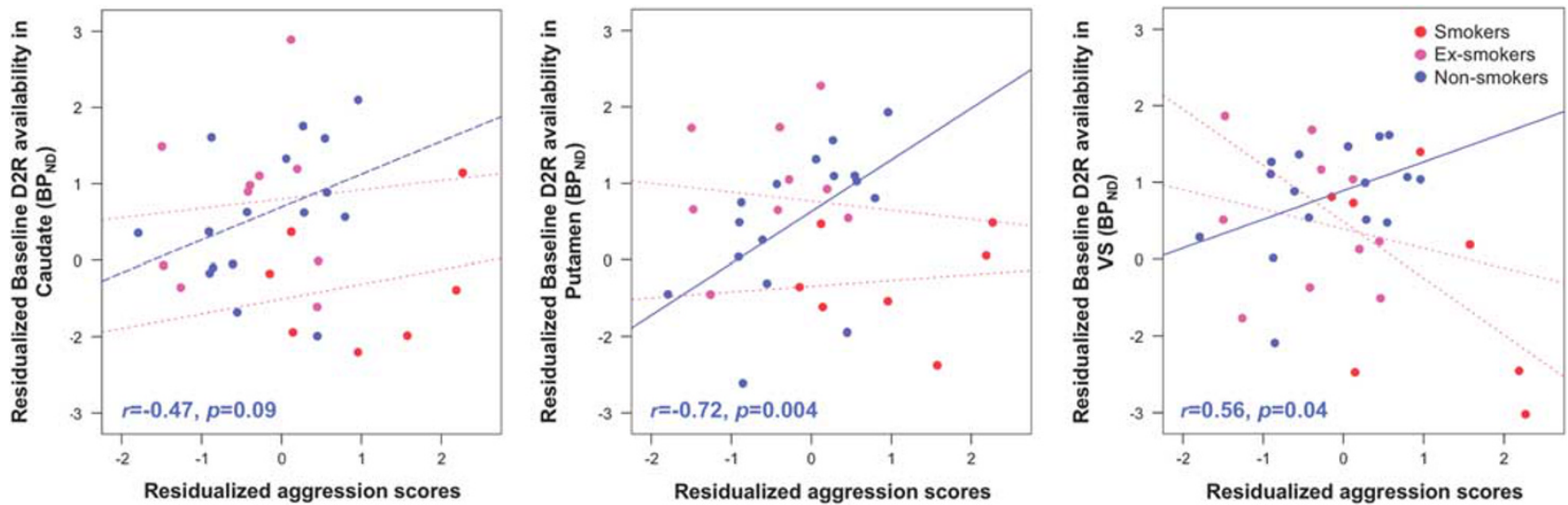

Figure 3 Aggression MPQ personality scores correlated with baseline D2R in putamen $(r=0.72, p=0.004$; Bonferroni-corrected), VS $(r=0.56, p=0.04)$, and at trend level in the caudate $(r=0.47, p=0.09)$ in nonsmokers only; variables have been residualized for age and BMI. There were no significant correlations for smokers or ex-smokers. BP $\mathrm{ND}$, nondisplaceable binding potential; DA, dopamine; VS, ventral striatum.

showed a trend of greater DA release than current smokers in caudate and putamen. Finally, we found that smokers had higher aggression and lower harm avoidance personality dimensions compared with ex-smokers and nonsmokers. Exploratory analyses showed that aggression scores correlated positively with striatal D2R in nonsmokers only.

Our findings of lower baseline striatal D2R availability in current smokers compared with nonsmokers is in line with previous findings (Albrecht et al, 2013; Brody et al, 2004; Fehr et al, 2008). Lower striatal $\mathrm{D} 2 \mathrm{R}$ availability has also been shown for other substance use disorders, including cocaine, methamphetamine, alcohol, and heroin (Volkow et al, 1990, 1996, 2001; Wang et al, 1997). Lower baseline striatal D2R availability has been associated with less successful treatment outcomes and higher chances of relapse in patients with methamphetamine and cocaine use disorder (Martinez et al,
2011; Wang et al, 2012; Wiers et al, 2016). For smokers, a recent study showed that nicotine dependence severity was negatively associated with striatal D2R availability (Okita et al, 2016a). However, different from findings in other substance use disorders that have shown attenuated DA increases when challenged with MP or amphetamine (Martinez et al, 2005; Volkow et al, 2014a; Wang et al, 2012), in our current study we did not find a significant difference in MP-induced DA release between current smokers and nonsmokers.

Studies on whether drug abstinence may increase striatal D2R availability are scarce. In the case of patients with an alcohol use disorder, D2R availability was found to increase 1 year after abstinence as compared with a baseline session (Rominger et al, 2012). On the other hand, no changes in striatal D2R were observed in methamphetamine abusers 9 months after detoxification compared with their baseline 
measures (Volkow et al, 2015). In the current study, we found that in ex-smokers striatal D2R availability did not differ from nonsmokers, suggesting that lower D2R availability in active smokers may normalize after abstinence. After MP administration, ex-smokers also showed stronger DA release in caudate and putamen compared with current smokers, suggesting a compensatory mechanism after abstinence. However, these effects were small and would not survive correction for multiple comparisons and are thus reported as preliminary. Previous findings measuring recovery of stimulant-induced DA release in substance abusers showed that in abstinent methamphetamine abusers (Wang et al, 2012) and in abstinent cocaine-dependent subjects (Martinez et al, 2011), DA release was similar to that in nondrug abusing controls consistent with recovery. Exsmokers have also shown normalized behavioral action tendencies towards smoking-related cues that were present in current smokers (Wiers et al, 2013), and that have been associated with striatal activation in patients with an alcohol use disorder (Wiers et al, 2014), further suggesting normalization of the DA system after smoking cessation.

The MPQ results showed that aggression and harm avoidance scores in current smokers were significantly different from both nonsmokers and ex-smokers (harm avoidance only at trend level; corrected for multiple comparisons), replicating results reported in a larger sample (Kahler et al, 2009). Higher aggression at adolescence has been linked to a higher likelihood of smoking (Welch and Poulton, 2009). In turn, higher aggression scores could also be because of smoking as the smoke in the cigarette has been shown to inhibit monoamine oxidase $\mathrm{A}\left(\mathrm{MAO}_{\mathrm{A}}\right)$ activity in the brain (Fowler et al, 1996). This is relevant as congenital deficiency of MAO-A in males has been associated with aggressive behaviors (Brunner et al, 1993); in healthy controls, levels of $\mathrm{MAO}_{\mathrm{A}}$ in brain were negatively correlated with aggression scores as measured by the MPQ (Alia-Klein et al, 2008). The increased harm avoidance scores, which measures an individual's likelihood to avoid actions or behaviors that may cause harm, found in ex-smokers may be interpreted as an effect of smoking cessation on this trait or as an underlying trait that might have helped smokers quit. Indeed, prior studies have shown that smokers with higher harm avoidance scores were more likely to remain abstinent after an attempt to quit smoking than those with lower scores (Cui et al, 2016). Moreover, the exploratory finding that aggression scores correlated positively with striatal D2R in nonsmokers is in line with previous animal studies showing positive associations between aggression and striatal D2R expression (Couppis et al, 2008; van Erp and Miczek, 2000).

The study findings may have been limited because of the small sample size of each of the group. The number of participants included in this study were based on the number of smokers and ex-smokers in healthy control groups of previous studies; and nonsmokers were matched based in demographics accordingly. The small sample size may account for the trend-wise effect of smoking status on MPinduced DA release. We reported effect sizes here to facilitate power analyses for future studies. In addition, smoking severity was not very high in the current and ex-smokers and varied widely within smokers (cigarettes/day ranged from 4 to 10 ) and ex-smokers (cigarettes/day ranged from 3 to 20), and very few participants represented severe cases of tobacco use disorders. Although demographic characteristics such as age, BMI, years of education, and smoking characteristics were similar between groups, future studies with larger sample sizes and more extreme current smokers and ex-smokers would help strengthen our results. Studies in larger sample sizes may also make it possible to assess gender differences. This is important as previous studies have shown gender differences in striatal D2R availability, smokinginduced DA release, and smoking behaviors overall (Brown et al, 2012; Cosgrove et al, 2014; Okita et al, 2016b). The current study compares three different groups with different participants and longitudinal prospective studies on the effects of smoking cessation are necessary to draw conclusions on the effects of smoking cessation on D2R availability and DA release. Another limitation is that participant's smoking characteristics were based on self-report interviews that included number of cigarettes used per day, years of use, age of smoking initiation, and number of quit attempts, and although we used breath CO levels to confirm smoking status we did not obtain standardized questionnaires of nicotine dependence such as the Fagerstrom. Furthermore, MRI images were not available for all participants, thus limiting our capacity to coregister images and determine striatal ROIs. However, we and others have shown that MRI coregistration does not improve quantification of $\left[{ }^{11} \mathrm{C}\right]$ raclopride binding (Kuhn et al, 2014; Wang et al, 1997). To minimize the acute effects of nicotine on $\left[{ }^{19} \mathrm{C}\right]$ raclopride binding, smokers were allowed to have a last cigarette $>2.5 \mathrm{~h}$ before PET scanning. However, because the temporal duration of the decreases in striatal D2R after cigarette smoking have not been investigated (Brody et al, 2004), we cannot rule out the possibility that the last cigarette of the smoking group may have affected their D2R measures. Finally, $\left[{ }^{11} \mathrm{C}\right]$ raclopride binds to both D2 and D3 receptors and whereas binding in dorsal striatum reflects mostly D2, as D3 receptor expression is very low, in VS the levels are similar (Seeman et al, 2006). Hence, in the current study we cannot differentiate the relative contribution of D2 versus D3 in the VS.

In sum, our study confirmed lower striatal D2R availability in current smokers compared with nonsmokers, and is the first in showing that ex-smokers showed higher striatal D2R availability compared with current smokers; suggesting recovery of the deficits in DA D2R signaling with smoking cessation in dorsal striatum. Studies in larger samples are needed to assess whether smoking status affects striatal DA release.

\section{FUNDING AND DISCLOSURE}

The authors declare no conflict of interest.

\section{ACKNOWLEDGMENTS}

The work was supported by the National Institutes of Health Intramural Research Program and grant number Y1AA-3009 to NDV.

\section{REFERENCES}

Albrecht DS, Kareken DA, Yoder KK (2013). Effects of smoking on $\mathrm{D}(2) / \mathrm{D}(3)$ striatal receptor availability in alcoholics and social drinkers. Brain Imag Behav 7: 326-334. 
Alia-Klein N, Goldstein RZ, Kriplani A, Logan J, Tomasi D, Williams B et al (2008). Brain monoamine oxidase A activity predicts trait aggression. J Neurosci 28: 5099-5104.

Brody AL, Mandelkern MA, Olmstead RE, Allen-Martinez Z, Scheibal D, Abrams AL et al (2009). Ventral striatal dopamine release in response to smoking a regular vs a denicotinized cigarette. Neuropsychopharmacology 34: 282-289.

Brody AL, Olmstead RE, London ED, Farahi J, Meyer JH, Grossman $\mathrm{P}$ et al (2004). Smoking-induced ventral striatum dopamine release. Am J Psychiatry 161: 1211-1218.

Brown AK, Mandelkern MA, Farahi J, Robertson C, Ghahremani DG, Sumerel B et al (2012). Sex differences in striatal dopamine D2/D3 receptor availability in smokers and non-smokers. Int J Neuropsychopharmacol 15: 989-994.

Brunner HG, Nelen M, Breakefield XO, Ropers HH, van Oost BA (1993). Abnormal behavior associated with a point mutation in the structural gene for monoamine oxidase A. Science 262: $578-580$

Busto UE, Redden L, Mayberg H, Kapur S, Houle S, Zawertailo LA (2009). Dopaminergic activity in depressed smokers: a positron emission tomography study. Synapse 63: 681-689.

Cosgrove KP, Wang S, Kim SJ, McGovern E, Nabulsi N, Gao H et al (2014). Sex differences in the brain's dopamine signature of cigarette smoking. J Neurosci 34: 16851-16855.

Couppis MH, Kennedy CH, Stanwood GD (2008). Differences in aggressive behavior and in the mesocorticolimbic DA system between A/J and BALB/cJ mice. Synapse 62: 715-724.

Cui Y, Tang R, Lam CY, Cinciripini PM, Robinson JD (2016). The influence of personality traits on smokers' affect, withdrawal and cessation intervention outcome. Addict Behav 54: 7-11.

Dang LC, Samanez-Larkin GR, Castrellon JJ, Perkins SF, Cowan RL, Zald DH (2016). Associations between dopamine D2 receptor availability and BMI depend on age. Neuroimage 138: 176-183.

Dani JA (2003). Roles of dopamine signaling in nicotine addiction. Mol Psychiatry 8: 255-256.

Fehr C, Yakushev I, Hohmann N, Buchholz HG, Landvogt C, Deckers $\mathrm{H}$ et al (2008). Association of low striatal dopamine d2 receptor availability with nicotine dependence similar to that seen with other drugs of abuse. Am J Psychiatry 165: 507-514.

Fiore MC, Jaen CR, Baker TB, Bailey WC, Benowitz NL, Curry SJ et al (2008). Treating tobacco use and dependence: 2008 update US Public Health Service Clinical Practice Guideline executive summary. Resp Care 53: 1217-1222.

Fowler JS, Volkow ND, Wang GJ, Pappas N, Logan J, Shea C et al (1996). Brain monoamine oxidase A inhibition in cigarette smokers. Proc Natl Acad Sci USA 93: 14065-14069.

Herman AI, DeVito EE, Jensen KP, Sofuoglu M (2014). Pharmacogenetics of nicotine addiction: role of dopamine. Pharmacogenomics 15: 221-234.

Innis RB, Cunningham VJ, Delforge J, Fujita M, Gjedde A, Gunn RN et al (2007). Consensus nomenclature for in vivo imaging of reversibly binding radioligands. J Cereb Blood Flow Metabol 27: 1533-1539.

Ishibashi K, Ishii K, Oda K, Kawasaki K, Mizusawa H, Ishiwata K (2009). Regional analysis of age-related decline in dopamine transporters and dopamine D2-like receptors in human striatum. Synapse 63: 282-290.

Jamal A, Homa DM, O'Connor E, Babb SD, Caraballo RS, Singh $\mathrm{T}$ et al (2015). Current cigarette smoking Among Adults - United States, 2005-2014. MMWR Morb Mortal Wkly Rep 64: 1233-1240.

Kahler CW, Daughters SB, Leventhal AM, Rogers ML, Clark MA, Colby SM et al (2009). Personality, psychiatric disorders, and smoking in middle-aged adults. Nicotine Tob Res 11: 833-841.

Kuhn FP, Warnock GI, Burger C, Ledermann K, Martin-Soelch C, Buck A (2014). Comparison of PET template-based and MRI-based image processing in the quantitative analysis of C11-raclopride PET. EJNMMI Res 4: 7.
Logan J, Fowler JS, Volkow ND, Wang GJ, Ding YS, Alexoff DL (1996). Distribution volume ratios without blood sampling from graphical analysis of PET data. J Cereb Blood Flow Metabol 16: 834-840.

Martinez D, Carpenter KM, Liu F, Slifstein M, Broft A, Friedman AC et al (2011). Imaging dopamine transmission in cocaine dependence: link between neurochemistry and response to treatment. Am J Psychiatry 168: 634-641.

Martinez D, Gil R, Slifstein M, Hwang DR, Huang Y, Perez A et al (2005). Alcohol dependence is associated with blunted dopamine transmission in the ventral striatum. Biol Psychiatry 58: 779-786.

Martinez D, Narendran R, Foltin RW, Slifstein M, Hwang DR, Broft A et al (2007). Amphetamine-induced dopamine release: markedly blunted in cocaine dependence and predictive of the choice to self-administer cocaine. Am J Psychiatry 164: 622-629.

Mizrahi R, Suridjan I, Kenk M, George TP, Wilson A, Houle S et al (2013). Dopamine response to psychosocial stress in chronic cannabis users: a PET study with [11C]-+-PHNO. Neuropsychopharmacology 38: 673-682.

Okita K, Mandelkern MA, London ED (2016a). Cigarette use and striatal dopamine D2/3 receptors: possible role in the link between smoking and nicotine dependence. Int J Neuropsychopharmacol 19: pyw074.

Okita K, Petersen N, Robertson CL, Dean AC, Mandelkern MA, London ED (2016b). Sex differences in midbrain dopamine D2type receptor availability and association with nicotine dependence. Neuropsychopharmacology 41: 2913-2919.

Patrick CJ, Curtin JJ, Tellegen A (2002). Development and validation of a brief form of the Multidimensional Personality Questionnaire. Psychol Assess 14: 150-163.

Rominger A, Cumming P, Xiong G, Koller G, Boning G, Wulff M et al (2012). [18F]Fallypride PET measurement of striatal and extrastriatal dopamine $D$ 2/3 receptor availability in recently abstinent alcoholics. Addict Biol 17: 490-503.

Seeman P, Wilson A, Gmeiner P, Kapur S (2006). Dopamine D2 and D3 receptors in human putamen, caudate nucleus, and globus pallidus. Synapse 60: 205-211.

Shumay E, Wiers CE, Shokri-Kojori E, Kim SW, Hodgkinson CA, Sun $\mathrm{H}$ et al (2017). New repeat polymorphism in the AKT1 gene predicts striatal dopamine D2/D3 receptor availability and stimulant-induced dopamine release in the healthy human brain. J Neurosci 37: 4982-4991.

Urban NB, Slifstein M, Thompson JL, Xu X, Girgis RR, Raheja S et al (2012). Dopamine release in chronic cannabis users: a [11c] raclopride positron emission tomography study. Biol Psychiatry 71: 677-683.

van de Giessen E, Weinstein JJ, Cassidy CM, Haney M, Dong Z, Ghazzaoui $\mathrm{R}$ et al (2017). Deficits in striatal dopamine release in cannabis dependence. Mol Psychiatry 22: 68-75.

van Erp AM, Miczek KA (2000). Aggressive behavior, increased accumbal dopamine, and decreased cortical serotonin in rats. J Neurosci 20: 9320-9325.

Volkow ND, Chang L, Wang GJ, Fowler JS, Ding YS, Sedler M et al (2001). Low level of brain dopamine D2 receptors in methamphetamine abusers: association with metabolism in the orbitofrontal cortex. Am J Psychiatry 158: 2015-2021.

Volkow ND, Fowler JS, Wolf AP, Schlyer D, Shiue CY, Alpert R et al (1990). Effects of chronic cocaine abuse on postsynaptic dopamine receptors. Am J Psychiatry 147: 719-724.

Volkow ND, Logan J, Fowler JS, Wang GJ, Gur RC, Wong C et al (2000). Association between age-related decline in brain dopamine activity and impairment in frontal and cingulate metabolism. Am J Psychiatry 157: 75-80.

Volkow ND, Tomasi D, Wang GJ, Logan J, Alexoff DL, Jayne M et al (2014a). Stimulant-induced dopamine increases are markedly blunted in active cocaine abusers. Mol Psychiatry 19: 1037-1043. 
Volkow ND, Tomasi D, Wang GJ, Telang F, Fowler JS, Logan J et al (2012a). Evidence that sleep deprivation downregulates dopamine D2R in ventral striatum in the human brain. J Neurosci 32: 6711-6717.

Volkow ND, Wang GJ, Fowler JS, Gatley SJ, Logan J, Ding YS et al (1998). Dopamine transporter occupancies in the human brain induced by therapeutic doses of oral methylphenidate. Am J Psychiatry 155: 1325-1331.

Volkow ND, Wang GJ, Fowler JS, Logan J, Gatley SJ, Hitzemann R et al (1997). Decreased striatal dopaminergic responsiveness in detoxified cocaine-dependent subjects. Nature 386: 830-833.

Volkow ND, Wang GJ, Fowler JS, Logan J, Gatley SJ, Wong C et al (1999). Reinforcing effects of psychostimulants in humans are associated with increases in brain dopamine and occupancy of D (2) receptors. J Pharmacol Exp Ther 291: 409-415.

Volkow ND, Wang GJ, Fowler JS, Logan J, Hitzemann R, Ding YS et al (1996). Decreases in dopamine receptors but not in dopamine transporters in alcoholics. Alcohol Clin Exp Res 20: $1594-1598$

Volkow ND, Wang GJ, Fowler JS, Logan J, Schlyer D, Hitzemann R et al (1994). Imaging endogenous dopamine competition with [11C]raclopride in the human brain. Synapse 16: 255-262.

Volkow ND, Wang GJ, Smith L, Fowler JS, Telang F, Logan J et al (2015). Recovery of dopamine transporters with methamphetamine detoxification is not linked to changes in dopamine release. Neuroimage 121: 20-28.

Volkow ND, Wang GJ, Telang F, Fowler JS, Alexoff D, Logan J et al (2014b). Decreased dopamine brain reactivity in marijuana abusers is associated with negative emotionality and addiction severity. Proc Natl Acad Sci USA 111: E3149-E3156.

Volkow ND, Wang GJ, Telang F, Fowler JS, Logan J, Jayne M et al (2007). Profound decreases in dopamine release in striatum in detoxified alcoholics: possible orbitofrontal involvement. J Neurosci 27: 12700-12706.
Volkow ND, Wang GJ, Tomasi D, Kollins SH, Wigal TL, Newcorn JH et al (2012b). Methylphenidate-elicited dopamine increases in ventral striatum are associated with long-term symptom improvement in adults with attention deficit hyperactivity disorder. J Neurosci 32: 841-849.

Wang GJ, Smith L, Volkow ND, Telang F, Logan J, Tomasi D et al (2012). Decreased dopamine activity predicts relapse in methamphetamine abusers. Mol Psychiatry 17: 918-925.

Wang GJ, Volkow ND, Fowler JS, Logan J, Abumrad NN, Hitzemann RJ et al (1997). Dopamine D2 receptor availability in opiate-dependent subjects before and after naloxoneprecipitated withdrawal. Neuropsychopharmacology 16: 174-182.

Wang GJ, Volkow ND, Fowler JS, Logan J, Pappas NR, Wong CT et al (1999). Reproducibility of repeated measures of endogenous dopamine competition with [11C]raclopride in the human brain in response to methylphenidate. J Nucl Med 40: 1285-1291.

Welch D, Poulton R (2009). Personality influences on change in smoking behavior. Health Psychol 28: 292-299.

Wiers CE, Cabrera E, Skarda E, Volkow ND, Wang GJ (2016). PET imaging for addiction medicine: From neural mechanisms to clinical considerations. Prog Brain Res 224: 175-201.

Wiers CE, Kuhn S, Javadi AH, Korucuoglu O, Wiers RW, Walter H et al (2013). Automatic approach bias towards smoking cues is present in smokers but not in ex-smokers. Psychopharmacology 229: 187-197.

Wiers CE, Stelzel C, Park SQ, Gawron CK, Ludwig VU, Gutwinski S et al (2014). Neural correlates of alcohol-approach bias in alcohol addiction: the spirit is willing but the flesh is weak for spirits. Neuropsychopharmacology 39: 688-697.

Yamaguchi Y, Lee YA, Kato A, Jas E, Goto Y (2017). The roles of dopamine D2 receptor in the social hierarchy of rodents and primates. Sci Rep 7: 43348. 